\title{
Diretivas de projeto e metodologia de implantação de um sistema aquapônico sustentável
}

Com o crescimento populacional mundial, a busca por inovações tecnológicas que aumentem a produção de alimentos, sem comprometer o meio ambiente imperativo e se constitui em temática importante discutida nos Objetivos do Desenvolvimento Sustentável. Neste cenário, a aquaponia, que associa a produção de vegetais à produção de peixes, se destaca, contribuindo com o desenvolvimento sustentável, pois melhora a produção de alimentos, promove a segurança alimentar, garante a disponibilidade e manejo sustentável da água e assegura padrões de produção sustentáveis. Contudo, a eficácia do sistema depende de bombas e mecanismos de aeração que consomem energia, se caracterizando em um entrave sustentável da técnica. 0 objetivo desta pesquisa foi elaborar diretivas e metodologias de implantação de um sistema de aquaponia sustentável para uma Instituição de Ensino Superior, buscando alternativas sustentáveis de manutenção energética. $O$ projeto propõe a construção de um laboratório de aquaponia com $80 \mathrm{~m}^{2}$, composto por um tanque para o cultivo de tilápias destinadas ao consumo e de carpas coloridas, cultivadas como peixe ornamental, calhas hidropônicas horizontais e em espiral para o cultivo de diferentes temperos, hortaliças e frutas, um tanque de filtro biológico alagado, contendo argila expandida e cultivo de papiro. O sistema de bombeamento dos efluentes para as calhas hidropônicas será acionado por energia fotovoltaica e o sistema de aeração, será movido por turbina eólica. A água que alimentará o sistema será proveniente da cisterna de aproveitamento de águas pluviais da instituição. Espera-se, com esta proposta, referenciar a implantação de sistemas de aquaponia sustentáveis sob o ponto de vista energético.

\section{Project and methodology directives for the implementation of a sustainable aquaponic system}

\begin{abstract}
With the worldwide population growth, the search for technological innovations that increase food production without compromising the environment is imperative and constitutes an important theme discussed in the Sustainable Development Objectives. In this scenario, aquaponics, which associates vegetable production with fish production, stands out, contributing to sustainable development, as it improves food production, promotes food security, ensure the availability and sustainable management of water and ensures. However, the effectiveness of the system depends on energy-consuming pumps and aeration mechanisms, which are characterized as a sustainable hindrance to the technique. The objective of this research will be to propose a pilot aquaponics system for a Higher Education Institution, seeking sustainable alternatives for energy maintenance. The project proposes the construction of an aquaponics laboratory with $80 \mathrm{~m}^{2}$, consisting of a tank for the cultivation of tilapia destined for consumption and of colored carp, grown as ornamental fish, horizontal and spiral hydroponic channels for the cultivation of different spices, vegetables and fruit, a biological filter tank flooded with expanded clay and papyrus cultivation, The effluent pumping system for the hydroponic gutters will be powered by photovoltaic energy and the aeration system will be powered by a wind turbine. The water that will feed the system will come from the rainwater harvesting cistern of the institution. It is hoped, with this proposal, to refer to the implementation of energy-efficient aquaponics systems.
\end{abstract}

Keywords: Renewable Energies; Hydroponics; Fish Production; Sustainability.

Topic: Desenvolvimento, Sustentabilidade e Meio Ambiente

Reviewed anonymously in the process of blind peer.
Received: 10/06/2018

Approved: 24/07/2018

Peiscilla Kohiyama de Matos Silva Siqueira (DD

Centro Universitário de Maringá, Brasil

http://lattes.cnpq.br/9056063477931422

http://orcid.org/0000-0003-4222-2886

priscilla.matos@unicesumar.edu.br

Márcia Aparecida Andreazzi (iD

Centro Universitário de Maringá, Brasil

http://lattes.cnpq.br/0356767742666814

http://orcid.org/0000-0002-4663-3837

marcia.andreazzi@unicesumar.edu.br

Edison Schmdit Filho (iD

Centro Universitário de Maringá, Brasil

http://lattes.cnpq.br/7605628504842582

http://orcid.org/0000-0001-9727-5024

edison.schmidt@unicesumar.edu.br

6

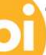

DOI: 10.6008/CBPC2179-6858.2018.005.0019

\begin{abstract}
Luciana Cristina Soto Herek Rezende
Centro Universitário de Maringá, Brasil

http://lattes.cnpq.br/1158006438170059

http://orcid.org/0000-0001-9677-4139

luciana.rezende@unicesumar.edu.br

Alessandra de Castro Silva Pedrangelo (it

Centro Universitário de Maringá, Brasil

http://lattes.cnpq.br/1107208976744754

http://orcid.org/0000-0002-0386-423X

alepedrangelo@gmail.com

Cleiltan Novais da Silva (id)

Centro Universitário de Maringá, Brasil

http://lattes.cnpq.br/9993910421974160

http://orcid.org/0000-0002-6194-1950

cleiltan@gmail.com
\end{abstract}

Referencing this:

SIQUEIRA, P. K. M. D.; ANDREAZZI, M. P.; SCHMDIT FILHO, E.; REZENDE, L. C. S. H.; PEDRANGELO, A. C. S.; SILVA, C. N.. Diretivas de projeto e metodologia de implantação de um sistema aquapônico sustentável. Revista Ibero Americana de Ciências Ambientais, v.9, n.5, p.209-217, 2018. DOI: http://doi.org/10.6008/CBPC21796858.2018.005.0019 


\section{INTRODUÇÃO}

As condições de vida humana no planeta estão ameaçadas, comprometendo a qualidade das gerações futuras, por isso, o modo de produção e consumo trazem sérias ameaças à população. $O$ aumento da população global, a rápida urbanização, a escassez de recursos naturais necessitam de formas sustentáveis de produção de alimento (RETIEF et al., 2016). O mundo precisa de soluções que busquem o aumento da produção de alimentos, sem comprometer ainda mais o meio ambiente, garantindo à população maior segurança alimentar e condições de igualdade (NASCIMENTO et al., 2012).

De fato, no Brasil durante os últimos anos, foram desenvolvidos estudos e projetos com o objetivo de difundir e aplicar sistemas sustentáveis na produção de alimentos além de promover a conscientização dos produtores e consumidores com relação a necessidade destes sistemas. O aumento da demanda por alimentos e a escassez de água elevam a necessidade de desenvolvimento de sistemas sustentáveis (TUNDISI, 2008).

A problemática da escassez de água no planeta, em conjunto com o aumento populacional nas áreas urbanas e a necessidade em produzir alimentos para atender a demanda crescente da população, vem constituindo um grande entrave mundial, sendo necessária a busca por sistemas sustentáveis de produção de alimentos que otimizem o espaço destinado ao cultivo.

Considerando as questões relacionadas à disponibilidade de solo e água, sabe-se que a produção de alimentos exige grandes volumes de água (DIVER, 2006). Neste contexto, emerge como alternativa de sistema sustentável de produção de alimentos, a técnica de aquaponia, que consiste no cultivo de vegetais, integrado à piscicultura, permitindo a redução de uso de água e o aproveitamento dos resíduos orgânicos. De acordo com Hundley et al. (2013), o sistema de recirculação de água da aquaponia reduz o impacto ao meio ambiente gerado pela produção de alimentos proporcionando uma economia de $90 \%$ no consumo de água destinado à produção de hortaliças em comparação ao cultivo tradicional.

Os principais pontos de destaque relacionados ao emprego desta técnica versam sobre o cultivo de peixes, compostos por fontes de proteína animal de elevada qualidade e produção de vegetais, como frutas e hortaliças, fontes de variados nutrientes, associado ao baixo consumo de água, reduzida produção de resíduos e menor ocupação de espaço, resultando em uma sinergia perfeita entre piscicultura, processos biológicos e plantas.

Desta forma, destaca-se outro ponto importante atual concernente à aquaponia, que é o fato de atender ao alcance de alguns dos Objetivos do Desenvolvimento Sustentável (ODS). Os ODS envolvem ações para acabar com a pobreza, promover a prosperidade e o bem-estar para todos, proteger o meio ambiente e enfrentar as mudanças climáticas e, discussões sobre produção de alimentos, consumo responsável e manejo sustentável da água estão elencadas e enfatizadas entre os objetivos (UNESCO, 2018).

Contudo, como pontos restritivos ao sistema, Dediu et al. (2012) afirmaram que, apesar da aquaponia envolver o funcionamento de dois sistemas de produção e gerar um rendimento extra para o 
produtor, a implantação destes dois sistemas resulta em maior investimento inicial e o cultivo dos vegetais e dos peixes deve estar em plena capacidade de produção a fim de garantir o retorno do investimento.

Associado a este fato, ressalta-se que o consumo de energia na aquaponia, decorrente dos sistemas de bombeamento e aeração também deve ser considerado. Camargo (2017) reporta que além da análise dos custos com a energia elétrica, a instalação de sistemas alternativos de energia, como o uso de energia solar, pode conferir maior segurança ao sistema aquapônico em situações de blackout, pois o comprometimento da aeração dos tanques pode resultar em alta mortalidade dos peixes. Portanto, na busca por um sistema produtivo, seguro e mais sustentável, recomenda-se o emprego de energias limpas ou renováveis.

O uso de fontes renováveis de energia e biocombustíveis como o biodiesel, o etanol, o hidrogênio, o biogás, a biomassa, a hidrelétrica, a maremotriz, a geotérmica, a energia eólica, solar e fotovoltaica alavanca o desenvolvimento sustentável, promove a diversificação, o desenvolvimento de novas tecnologias, a descentralização da produção energética e minimiza os impactos ambientais, diminuindo as emissões de $\mathrm{CO}_{2}$ e ameniza a dependência energética dos combustíveis fósseis (NASCIMENTO et al., 2012).

O Brasil, devido a sua extensão territorial, incidência solar e grande área costeira, é um país promissor na produção de energias renováveis (PINTO et al., 2017), sobretudo eólica e solar (SCHMIDT et al., 2016). Estas tecnologias emergem como alternativa de geração complementar e de expansão da capacidade geradora e suas aplicações devem ser estimuladas nos mais diferentes segmentos, inclusive em sistemas de aquaponia.

O sistema de produção aquapônico é uma técnica utilizada com sucesso em muitos países, como Estados Unidos, Austrália e também em países europeus, contudo, no Brasil o emprego comercial desta técnica ainda é discreto (HUNDLEY et al., 2013). Por isso, e considerando o baixo consumo de água, a produção de duas fontes de alimento e renda em um único sistema e a contribuição com a redução de impactos ambientais gerados pela produção de alimentos, a realização de estudos que forneçam informações que permitam a implantação deste sistema sob condições brasileiras são fundamentais (GEISENHOFF et al., 2016) e capazes de contribuir com o desenvolvimento sustentável.

Desta forma, o objetivo desta pesquisa foi elaborar diretivas de projeto e metodologia de implantação de um sistema aquapônico sustentável para uma Instituição de Ensino Superior localizada na região sul do estado do Paraná/ Brasil, acionado por fontes de energia limpa eólica e solar, a fim de contribuir na busca por sistemas de produção de alimentos mais eficientes, sustentáveis e energeticamente seguros.

\section{METODOLOGIA}

O método de pesquisa foi definido por duas etapas sequenciais governadas por estratégia de pesquisa teórico-conceitual, que envolveu as atividades de revisão de literatura e o desenvolvimento da proposta do projeto modelo. Para elaboração do projeto modelo foram consideradas as seguintes diretrizes: O local foi definido como a área urbana de uma Instituição de Ensino Superior (IES), localizada na cidade de Curitiba, Paraná, Brasil (latitude: 25 25' 40" S, longitude: 49 16' 23" W, altitude: 934 m) e a dimensão do sistema de aquaponia foi baseado na disponibilidade de área da IES; Para definição dos vegetais a serem 
cultivados no sistema, foi aplicado um questionário aos docentes e técnicos dos laboratórios do curso de gastronomia da IES a fim de se estabelecer os tipos e frequência de utilização dos principais vegetais utilizados nas aulas práticas realizadas no curso de graduação em Gastronomia; A definição dos peixes foi pautada em cultivo de espécie para consumo associado ao cultivo de espécie ornamental, buscando espécies adaptadas ao clima da região, mais tolerantes e resistentes ao manejo e as altas densidades de estocagem; Como fonte de energia para acionar o sistema, foi elaborado projeto elétrico baseado no emprego de energia renovável.

\section{DISCUSSÃO TEÓRICA}

Baseado na disponibilidade de área da IES, a dimensão do laboratório piloto de aquaponia foi definida em uma área total de $80 \mathrm{~m}^{2}(8 \mathrm{~m} \times 10 \mathrm{~m})$ com pé direito de 4 metros de altura. A estrutura do laboratório de aquaponia será de uma estufa em arco, de perfis fabricados com chapas de aço, galvanizadas em banho de zinco fundente. A estufa será coberta com filme agrícola importado (Suncover ${ }^{\circledR}$ Difusor 120 micras Ginegar Polysack ${ }^{\circledR}$ ) e o fechamento das frontais, laterais e elipses será realizada com tela anti afídeo (Ginegar Polysack ${ }^{\circledR}$ ). O piso será de paver, que são revestimentos feitos de concreto e um pergolado de madeira itaúba e pinnus autoclavado, medindo 2,5m de largura e 10 metros de comprimento, será instalado na parte frontal do laboratório.

Baseado nos objetivos de produção de vegetais e peixes para a IES definiu-se como constituintes do projeto piloto (Figura 1): 2 tanques de policloreto de vinil (PVC), com capacidade de 750 litros cada, medindo 0,861 m de altura, diâmetro inferior de 1,053m e diâmetro superior de 1,308m, para o cultivo de tilápias; 1 tanque de vidro incolor, espessura de $19 \mathrm{~mm}$, com capacidade de 1500 litros, medindo $1 \mathrm{~m}$ de altura, $1 \mathrm{~m}$ largura e 1,5m de comprimento, para o cultivo das carpas coloridas; 8 calhas hidropônicas de PVC, horizontais, com comprimento de 6 metros cada, e com espaçamento entre furos de $12,5 \mathrm{~cm}$, para o cultivo de hortaliças; 2 sistemas hidropônicos, em espiral, com mangueiras plásticas semi-rígidas de $100 \mathrm{~mm}$ de diâmetro; 1 tanque de filtro biológico alagado, com um reservatório circular de 500 litros de PVC, contendo argila expandida e cultivo de papiro (Cyperus papyrus).

Sistema de geração de energia limpa: 4 placas fotovoltaicas de policristalino de 150 watts (Yingli solar ${ }^{\circledR}$ ), variando conforme a intensidade solar, 02 baterias estacionárias freedom de 70 Ah (Heliar $\left.{ }^{\circledR}\right), 1$ controlador de carga de 10 ampéres (Victron ${ }^{\circledR}$ ), uma moto bomba de $3 / 4$ CV para a recirculação (Kajima ${ }^{\circledR}, 1 / 2$ HP Eletrobomba QB60); 1 turbina eólica composta por seis aletas, elaboradas com tubos de PVC, de $1 \mathrm{~m}$ de comprimento.

Com referência aos sistemas de cultivos dos vegetais na aquaponia, destaca-se o uso de bandejas flutuantes ou floating rafts, calhas hidropônicas ou NFT (Nutrient Film Technique) e Media-filled bed ou gravel bed. Para este projeto, foi definido o sistema de produção com calhas hidropônicas ou NFT, dispostas paralelamente. Estas calhas ou tubos de PVC contêm berçários, com espaçamento definido de acordo com a espécie a ser cultivada para disposição das mudas das plantas. Neste sistema, as raízes são alimentadas com uma fina camada de água com nutrientes que percorre a tubulação (GUERRERO-MONROY et al., 2012). 


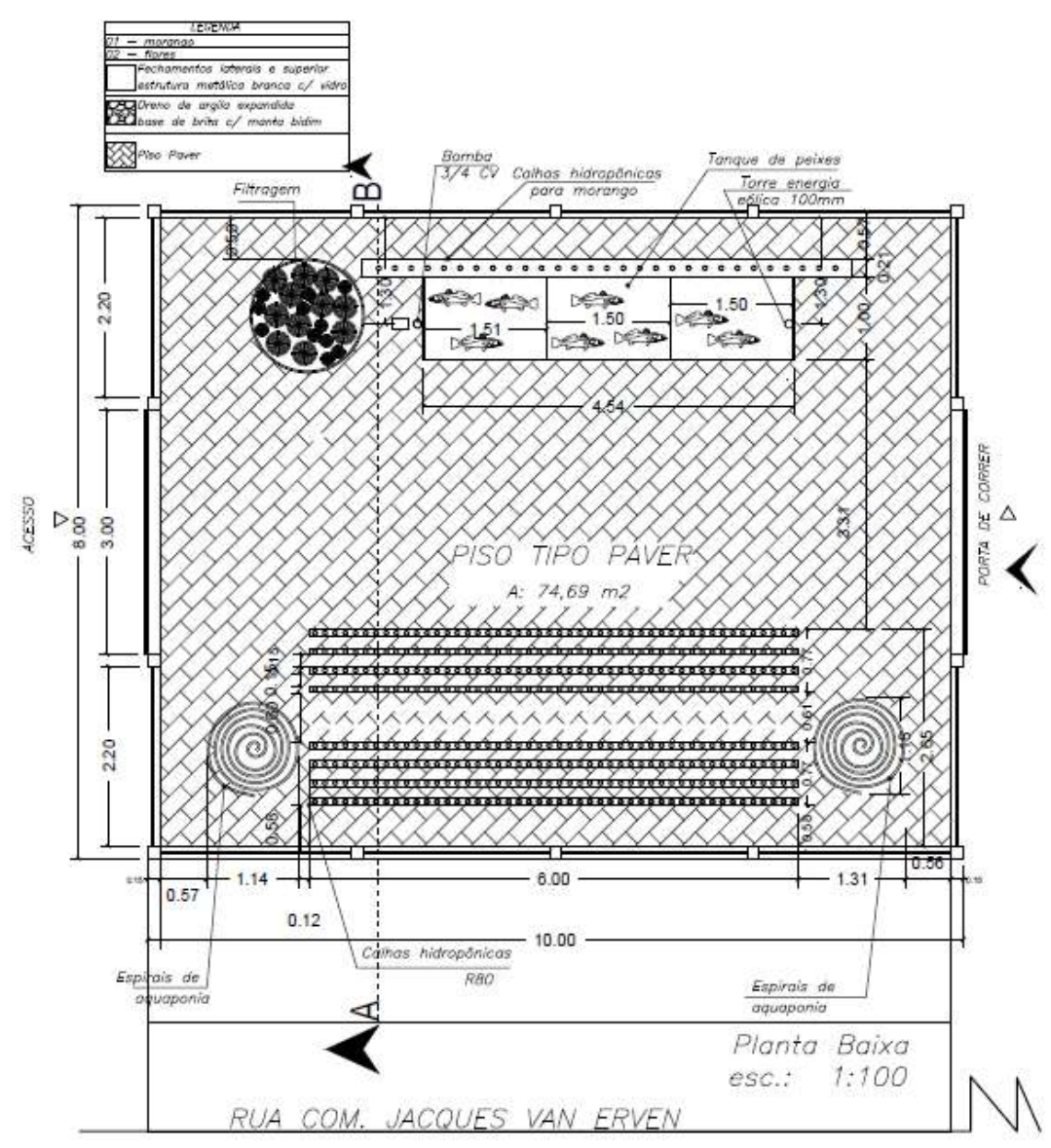

Figura 1: Estrutura experimental do laboratório de aquaponia.

Os resultados obtidos a partir dos questionários aplicados entre docentes e responsáveis pela elaboração das aulas práticas do Curso de Gastronomia, ofertado pela IES, definiram a escolha dos vegetais a serem cultivados nas calhas do sistema, sendo classificados em três grupos: temperos - alecrim (Rosmarinus officinalis), cebolinha (Allium schoenoprasum), hortelã (Mentha spicata), manjericão (Ocimum basilicum), salsinha (Petroselinum crispum) e sálvia (Salvia officinalis); hortaliças - agrião (Rorippa nasturtium-aquaticum), alface americana (Lactuca sativa), alface crespa (Lactuca sativa var. crispa), tomate (Solanum lycopersicum) e tomate cereja (Solanum lycopersicum var. cerasiforme); frutas - morango (Fragaria $\mathrm{x}$ ananassa). Conforme mencionado, as calhas foram dimensionadas com 6 metros de comprimento e espaçamento entre orifícios de 12,5 cm, ou seja, serão cultivadas, aproximadamente, 48 plantas por calha, perfazendo um total de 384 plantas por ciclo da cultura. A sinergia do cultivo dos vegetais, como temperos, hortaliças e frutas, no laboratório de aquaponia com as aulas práticas desenvolvidas pelo curso de Gastronomia, possibilitará um viés sustentável de produção e consumo local.

Os tanques de vidro para a criação de peixes serão subdivididos e foram definidas duas espécies para cultivo no sistema aquapônico: Tilápia do Nilo (Oreochromis niloticus) e Carpa Colorida (Cyprinus carpio), cujos alevinos serão adquiridos de produtores regionais. As Carpas Coloridas serão cultivadas no reservatório de vidro e a espécie Tilápia do Nilo, nos dois tanques de PVC.

A produção hidropônica possui o seu ciclo variável conforme a espécie, de 25 a 90 dias, e o ciclo dos peixes tem a duração de aproximadamente 210 a 270 dias. De acordo com Rakocy et al. (2006) a proporção 
dos volumes dos tanques de criação de peixes e do cultivo hidropônico varia entre 1:1 à 1:4. Já Nelson (2007) dimensiona para cada $1 \mathrm{~kg}$ de peixe, $7 \mathrm{~kg}$ de vegetais. Conforme cartilha da Food and Agriculture Organization of the United Nations (FAO, 2014), a densidade máxima de estocagem de peixes deverá ser de $20 \mathrm{~kg}$ de peixe por mil litros de água. Neste projeto, será considerada uma densidade populacional de 100 peixes por metro cúbico (COÊLHO et al., 2014).

A escolha da espécie Tilápia do Nilo se justifica, pois, segundo BACCARIN et al. (2009), é um peixe tolerante a manejos frequentes e a altas densidades de estocagem, apresenta boa conversão alimentar e possui seu ciclo de produção de 6 a 7 meses, e devido a estas caraterísticas, esta espécie de peixe é amplamente cultivada nos sistemas aquapônicos. Corroborando, Dediu et al. (2012) afirmaram que a escolha correta das espécies de peixes constitui uma estratégia para maximizar os lucros do sistema e que, atualmente, a principal espécie utilizada comercialmente é a tilápia.

Além disso, o cultivo das tilápias visa atender, sobretudo, as necessidades de insumos para as aulas práticas do curso de graduação em Gastronomia, ocorrentes na IES e, para tanto, a despesca acontecerá com os peixes adultos, com idade em torno de 210 dias, pesando em média 0,500 kg cada peixe.

A carpa colorida será cultivada como peixe ornamental e constitui uma espécie muito resistente a variações nos parâmetros de qualidade da água e tolerante a altas densidades de estocagem. $\mathrm{O}$ cultivo de uma espécie ornamental visa atender a finalidade educacional da IES e a manutenção de peixes com idades diferentes para suprir a entrada de insumos no cultivo hidropônico, pois, conforme Rakocy et al. (2006), as taxas de entrada de insumos quando se cultiva somente alevino é reduzida em até $90 \%$.

O filtro biológico para remoção dos sólidos e amônia será composto por argila expandida e cultivo de papiro (Cyperus papyrus). Este sistema permitirá a adesão das colônias de bactérias nitrossomonas e nitrobacters no sistema rizosférico e na superfície da argila expandida. O filtro de sólidos é necessário para evitar o entupimento do sistema pelos resíduos sólidos gerados. Existem várias opções de filtros decantadores, porém, o mais eficiente é o modelo com fundo cônico, onde os resíduos se sedimentam e podem ser retirados por meio de uma válvula instalada na sua base (EMBRAPA, 2015).

Concernente aos processos biológicos do sistema sabe-se que na aquaponia existe um fluxo contínuo de nutrientes entre diferentes organismos vivos e processos biológicos presentes, dentre eles, a nitrificação bacteriana. $O$ nitrogênio orgânico existente nos resíduos de ração não ingeridos pelo sistema de aquicultura é decomposto em amônia, por meio de microrganismos heterotróficos presentes na água, podendo ocasionar toxicidade às plantas e peixes, sendo necessária a remoção da amônia.

O papel de conversão da amônia $\left(\mathrm{NH}_{3}\right)$ em nitrito $\left(\mathrm{NH}_{2}{ }^{-}\right)$e este em nitrato $\left(\mathrm{NH}_{3}{ }^{-}\right)$transformando substâncias tóxicas em nutrientes benéficos para a hidroponia é realizado pelas bactérias nitrificantes. Os limites máximos de nitrogênio na forma de amônia total em viveiros de aquicultura devem estar entre 0,4 e 2,0 mg L-1 (BOYD et al., 2012).

O nitrogênio constitui um nutriente essencial para o desenvolvimento das plantas e, na forma de nitrato, possui uma maior taxa de absorção, por isto o manejo das colônias de bactérias é fundamental para o sistema. Algumas plantas, como o agrião (Nasturtium officinale), o lírio do brejo (Hedychium coronarium), 
o papiro (Cyperus papyrus) e a taboa (Typha domingensis), têm capacidade de reduzir os níveis de amônia por meio da absorção em seu sistema radicular e são utilizadas como filtros biológicos (DEDIU et al., 2012). Baseado no exposto elegeu-se o filtro biológico alagado constituído por argila expandida e cultivo de papiro (Cyperus papyrus).

O fornecimento de água para o sistema será proveniente da cisterna de aproveitamento de águas pluviais da IES, que possui a captação da água das chuvas em uma área de cobertura de $3.026,7 \mathrm{~m}^{2}$. Contribuindo para a sustentabilidade da proposta deste projeto utilizando água proveniente da chuva. Para implantação do projeto piloto de aquaponia intentando um sistema sustentável energeticamente, foi idealizado o emprego de duas formas de energia limpa: eólica e solar fotovoltaica. Contudo, buscando a segurança energética, o funcionamento do sistema poderá ser alternado para a rede elétrica convencional, caso haja necessidade.

O emprego de uma turbina eólica foi considerado para geração da energia a ser consumida nos processos de aeração dos tanques de cultivo. O sistema de aeração da aquaponia deve ser adequado para os peixes, plantas e bactérias nitrificantes do filtro biológico. Em clima tropical, a quantidade de oxigênio dissolvido na água deve ser superior a $3 \mathrm{mg} / \mathrm{L}$ e pode ser mantida pelo emprego de compressores ou sopradores de ar (aeradores) (RAKOCY et al., 2006). Carneiro et al. (2015) reportaram que a aeração deve estar presente no tanque de aquicultura e, conforme o design do sistema, difusores também devem ser instalados em outros compartimentos, como o ambiente de cultivo das plantas.

Camargo (2017) discorre sobre a instalação de sistemas alternativos de energia em cultivos aquapônicos tendo em vista a maior segurança energética do sistema em situações de blackout que podem causar prejuízo na aeração dos tanques e resultar em alta mortalidade dos peixes. O sistema de aeração deste projeto será movido por energia eólica gerada a partir de uma turbina eólica de fabricação artesanal instalada ao lado direito do laboratório, composta por seis aletas, elaboradas com tubos de PVC, de $1 \mathrm{~m}$ de comprimento cada.

A energia fotovoltaica será empregada para o funcionamento das bombas de circulação dos efluentes. Em função de o terreno ser nivelado, para que possa promover a circulação do efluente do reservatório de peixes para o filtro alagado e na sequência para as calhas e tubos helicoidais hidropônicos, será necessária a instalação de uma moto bomba de $3 / 4 \mathrm{CV}$ para a recirculação (Kajima ${ }^{\circledR}$, $1 / 2 \mathrm{HP}$ Eletrobomba QB60). Para alimentar esta bomba, serão instaladas na lateral do laboratório 4 placas de energia fotovoltaicas de policristalino de 150 watts, com $10^{\circ}$ de inclinação, 01 controlador de carga e 1 bomba trifásica em corrente contínua de 3/4. O dimensionamento considerou as características da carga, condições de irradiação local, local de instalação e demanda real da carga.

A inclinação dos coletores fotovoltaicos do sistema potencializa o aproveitamento do recurso, por isso considera-se o posicionamento em ângulo igual à latitude do local, entretanto, as condições climáticas de cada local devem ser avaliadas. Em locais próximos da linha do Equador, como é o caso de Curitiba, cidade onde será instalado o laboratório piloto, é indicado um ângulo mínimo de $10^{\circ}$, o que evita o acúmulo de sujeira nos módulos e facilita a limpeza natural pelas chuvas (PINHO et al., 2014). 
As fontes renováveis de energia alavacam o desenvolvimento sustentável, promovem a diversificação das fontes, o desenvolvimento de novas tecnologias e descentralização da produção energética e minimizam os impactos ambientais desta extração, diminuindo as emissões de $\mathrm{CO}_{2}$ e amenizam a dependência energética dos combustíveis fósseis (NASCIMENTO et al., 2012).

O Brasil, com suas características continentais e sua localização geográfica, é favorável para o aproveitamento das fontes de energia eólica e solar (TOLMASQUIM, 2016). A geração de energia eólica tem crescido nos últimos anos no Brasil, mas, com relação a energia fotovoltaica, sabe-se que a exploração da energia solar no Brasil é discreta perante o seu grande potencial. O desenvolvimento de um sistema de aquaponia movido por energias limpas, como a eólica e a fotovoltaica, pode tanto tornar o sistema mais sustentável quanto estimular o emprego destas fontes renováveis.

\section{CONCLUSÕES}

Os estudos teóricos e o desenvolvimento de uma proposta de um projeto piloto para um sistema de aquaponia para uma Instituição de Ensino Superior se mostraram exequíveis. A aquaponia colabora com o alcance de alguns Objetivos do Desenvolvimento Sustentável, como produção de alimentos, consumo responsável e manejo sustentável da água, contudo, na busca por um sistema produtivo e mais sustentável, recomenda-se que os sistemas aquapônicos sejam acionados por energias limpas ou renováveis. O Brasil, devido a sua dimensão e localização geográfica é um país promissor para o aproveitamento das fontes de energia eólica e solar, por isso, sugere-se a implantação de projetos de aquaponia acionados por estas fontes energéticas.

\section{REFERÊNCIAS}

BACCARIN, A. E.; LEONARDO, A. F. G.; TACHIBANA, L.; CORREIA, C. F.. Piscicultura em comunidade remanescente de quilombo: um estudo de caso. Informações Econômicas, São Paulo, v.39, n.11, p.42-47, 2009.

BOYD, C. E.; TUCKER, C. S.. Pond aquaculture water quality management. Boston: Springer Science \& Business Media, 2012.

CAMARGO, J.. Aquaponia economiza $90 \%$ da água usada na produção. Informe técnico. 2017.

CARNEIRO, P. C. F.; MARIA, A. N.; NUNES, M. U. C.; FUJIMOTO, R. Y.. Aquaponia: produção sustentável de peixes e vegetais. In: TAVARES-DIAS M.; MARIANO, W. S. Aquicultura no Brasil: novas perspectivas. São Carlos: Pedro \& João, 2015. p.429.

COÊLHO, A. A. C.; BEZERRA, J. H. C.; SILVA, J. W. A.; MOREIRA, R. T.; ALBUQUERQUE, L. F. G.; FARIAS, W. R. L.. Desempenho zootécnico de alevinos de tilápia do Nilo cultivados em um sistema de recirculação de água com a microalga Spirulina platensis. Revista Brasileira de Saúde e Produção Animal, Salvador, v.15, n.1, p.149-159, 2014. DOI: http://dx.doi.org/10.1590/S1519-99402014000100024
DEDIU, L.; CRISTEA, V.; XIAOSHUAN, Z.. Waste production and valorization in an integrated aquaponic system with bester and lettuce. African Journal of Biotechnology, Nairobi, v.11, n.9, p.2349-2358, 2012. DOI: http://dx.doi.org/10.5897/AJB11.2829

DIVER, S.. Aquaponics: Integration of hydroponics with aquaculture. National Sustainable Agriculture Information Service/ATTRA, 2006.

EMBRAPA. Empresa Brasileira de Pesquisa Agropecuária. Produção integrada de peixes e vegetais em aquaponia. Aracaju: Embrapa Tabuleiros, 2015.

FAO. Food and agriculture organization of the united nations. Small-scale aquaponic food production: Integrated fish and plant farming. Roma: Fisheries and Aquaculture Technical Paper, 2014

GEISENHOFF, L. O.; JORDAN, R. A.; SANTOS, R. C.; OLIVEIRA, F. C.; GOMES, E. P.. Effect of different substrates in aquaponic lettuce production associated with intensive tilapia farming with water recirculation systems. Engenharia Agrícola, Jaboticabal, v.36, n.2, p.291-299, 2016. DOI: http://dx.doi.org/10.1590/1809-4430-Eng.Agric.v36n2p291299/2016 
GUERRERO-MONROY, I.; DEL VIVAR, A. R.; FÉLIX-GASTELUM, R.. Integrated culture of white shrimp (Litopenaeus vannamei) and tomato (Lycopersicon esculentum Mill) with low salinity groundwater: management and production.

Aquaculture, v.366-367, p.76-84, 2012. DOI:

https://doi.org/10.1016/j.aquaculture.2012.09.003

HUNDLEY, G. M. C.; NAVARRO, R. D.; FIGUEIREDO, C. M. G.; NAVARRO, F. K. S. P.; PEREIRA, M. M.; RIBEIRO FILHO, O. P.; SEIXAS FILHO, J. T.. Aproveitamento do efluente da produção de tilápia do Nilo para o crescimento de manjericão (Origanum basilicum) e manjerona (Origanum majorana) em sistemas de aquaponia. Revista Brasileira de Agropecuária Sustentável, Viçosa, v.3, p.51-55, 2013. DOI: http://www.locus.ufv.br/handle/123456789/17959

NASCIMENTO, T. C.; MENDONÇA, A. T. B.; CUNHA, S. K.. Inovação e sustentabilidade na produção de energia o caso do sistema setorial de energia eólica no Brasil. Cadernos EBAPE.BR, Rio de Janeiro, v.10, n.3, 2012.

NELSON, R. L.. Ten aquaponic systems around the world. Aquaponics Journal, Montello, v.46, p.8-12, 2007.

UNESCO. Organização das nações unidas para a educação a ciência e a cultura. Agenda de Desenvolvimento pós-2015 UNESCO e os Objetivos de Desenvolvimento Sustentável. 2018.

PINHO, J; GALDINO, M. A.. Manual de Engenharia para Sistemas Fotovoltaicos. Rio de Janeiro, 2014.
PINTO, L. I. C.; MARTINS, F. R.; PEREIRA, E. B. P.. O mercado brasileiro da energia eólica, impactos sociais e ambientais. Revista Ambiente e Água, Taubaté, v.12, n.6, p.1082-1100, 2017. DOI: http://dx.doi.org/10.4136/ambi-agua.2064

RAKOCY, J. E.; MASSER M. P.; LOSORDO, T. M.. Recirculating aquaculture tank production systems: Aquaponics Integrating fish and plant culture. SRAC Publication, Mississipi, v.454, p.1-16, 2006.

RETIEF, F.; BOND, A.; POPE, J.; SAUNDERS, A.; KING, N.. Global megatrends and their implications for environmental assessment practice. Environmental Impact Assessment Review, v.61, p.52-60. 2016. DOI: https://doi.org/10.1016/j.eiar.2016.07.002

SCHMIDT, J.; CANCELLA, R.; PEREIRA JÚNIOR, A. O.. An optimal mix of Schmidt PV, wind and hydro power for a lowcarbon electricity supply in Brazil. Renewable Energy, Lemesos, v.85, p.137-147, 2016. DOI: http://doi.org/10.1016/i.renene.2015.06.010

TOLMASQUIM, M. T.. Energia renovável: hidráulica, biomassa, eólica, solar, oceânica. Rio de Janeiro: EPE, 2016.

TUNDISI, J. G.. Recursos hídricos no futuro: problemas e soluções. Estudos Avançados. São Paulo, v.22, n.63, p.7-16, 2008. DOI: http://doi.org/10.1590/S010340142008000200002

A CBPC - Companhia Brasileira de Produção Científica (CNPJ: 11.221.422/0001-03) detém os direitos materiais desta publicação. Os direitos referem-se à publicação do trabalho em qualquer parte do mundo, incluindo os direitos às renovaç̃ões, expansões e disseminações da contribuiç̃o, bem como outros direitos subsidiários. Todos os trabalhos publicados eletronicamente poderão posteriormente ser publicados em coletâneas impressas sob coordenação da Sustenere Publishing, da Companhia Brasileira de Produção Científica e seus parceiros autorizados. Os (as) autores (as) preservam os direitos autorais, mas não têm permissão para a publicação da contribuição em outro meio, impresso ou digital, em português ou em tradução. 